\title{
Los vaivenes de la política exterior argentina re-democratizada (1983-2013). Reflexiones sobre el impacto de los condicionantes internos
}

\author{
Ups and downs of Argentinean foreign policy in \\ democracy (1983-2013). The impact of domestic \\ constraints
}

Anabella Busso*

\section{Resumen}

La estabilidad institucional vigente en la Argentina desde finales de 1983 no trajo consigo un escenario de continuidad para la política exterior. Frente a esto, este artículo sostiene que, sin desconocer el impacto de las variables sistémicas, los vaivenes de la política exterior se explican mayoritariamente por causas internas entre las cuales se destacan las crisis político/económicas, las tensiones entre los distintos modelos de desarrollo y sus respectivas estrategias de inserción internacional y las variaciones en la concepción de democracia. Consecuentemente, se hará una revisión breve de estas causas analizando su impacto en el devenir de la política exterior.

Palabras clave: política exterior, Argentina, condicionantes internos, democracia, modelo de desarrollo.

\section{Abstract}

The current institutional stability in Argentina since late 1983 did not bring a favorable scenario for foreign policy continuity. Therefore, this

Profesora titular de la Facultad de Ciencia Política y Relaciones Internacionales de la Universidad Nacional de Rosario, Argentina. <gmarini@netizen.com.ar> Recibido el 11 de septiembre de 2013; aceptado el 4 de diciembre de 2013 
paper argues that without dismissing the impact of external constraints, the ups and downs of Argentinean foreign policy can be explained mostly by domestic causes, among them: the political and economic crises, tensions among different economic development models -and their respective strategies for international insertion- and diverse understandings of democracy. Consequently, we analyze the impact of those causes on foreign policy.

KEYWORDs: foreign policy, Argentina, domestic conditions, democracy, development model. 
ANABella Busso • Los vaivenes de la política exterior argentina re-democratizada...

La Argentina retornó a la democracia en octubre de 1983. Desde el punto de vista de la continuidad del sistema político la experiencia ha sido exitosa. Sin embargo, varias de sus políticas públicas, entre ellas la política exterior, han mostrado un devenir cambiante. En ese marco, este trabajo parte del supuesto de que más allá de las influencias provenientes del contexto internacional, las principales causas de los vaivenes de la Política Exterior Argentina (PEA) han sido de orden interno.

Consecuentemente, parte de la literatura especializada coincide en señalar que desde 1983 hasta nuestros días, la PEA atravesó por diferentes períodos mostrando cambios, ajustes ${ }^{1}$ y pocas continuidades. Por ello, los análisis de este devenir subrayan con frecuencia el carácter errático, la inconsistencia e incluso la ausencia de una PEA. En este marco, los autores concuerdan en que la variable cambio de régimen explica claramente las diferencias entre la acción externa del gobierno militar instalado a partir de 1976 y la aplicada por los gobiernos democráticos. Sin embargo ese acuerdo no es tan amplio al momento de explicar, más allá de los cambios de gobierno, las razones de la inestabilidad de la PEA en democracia.

1 Roberto Russell, puso de relieve la «distinción entre cambio de política exterior, que implica un realineamiento de un país con respecto a las principales coaliciones, fisuras globales o regionales; y un ajuste de política exterior, que ocasiona alteraciones en el comportamiento de política exterior, que sin embargo no implican un realineamiento básico» (Russell, 1990).
En este marco sostenemos a modo de hipótesis que, además de las cuestiones sistémicas que han sido muy significativas, las principales causas que explican los vaivenes de la política exterior en democracia son las crisis político/económicas, las tensiones entre los distintos modelos de desarrollo y sus respectivas estrategias de inserción internacional y las variaciones en la concepción de democracia.

En función de esta afirmación, haremos una caracterización de las mencionadas causas y una revisión breve de la influencias de estas en los cambios y ajustes de la PEA en los gobiernos de Alfonsín, Menem y Néstor y Cristina Kirchner.

FuENTES INTERNAS DE

INESTABILIDAD EN LA POlítica

\section{EXTERIOR ARgENTINA}

Tal como afirmamos más arriba, entre las principales causas internas que pueden contribuir a explicar las inconsistencias de la PEA de los últimos 30 años se destacan el debate en torno a los modelos de desarrollo, las recurrentes crisis económico-políticas y las diversas concepciones de democracia.

De manera acotada, podríamos afirmar que Argentina es un país que no ha podido aún saldar el debate histórico sobre cuál es el modelo de desarrollo más adecuado para la nación. Este debate, que involucra intereses económicos encontrados, lleva también a la 
discusión entre diferentes concepciones de democracia y de PE.

Las disputas en torno al modelo de desarrollo involucran, al menos, dos propuestas. Una de ellas tiene sus bases en las ideas estructural-desarrollistas y autonomistas que en ocasiones forman parte de los programas de los partidos mayoritarios (Paradiso, 2007: 23). La otra revitaliza interpretaciones que adjudican la génesis de la declinación argentina a la industrialización mercado-internista cimentada desde la posguerra, contrastándola con la Argentina abierta de principios del siglo XX, basada en el modelo agroexportador y la conexión especial con una gran potencia (Rapoport y Spiguel, 2005:72-73). Desde la perspectiva de estos autores la revitalización operó como legitimación del proceso de desindustrialización impuesto a partir de 1976 y estuvo en la base de las formulaciones que justificaron la política exterior de los años noventa, mientras que la primera está más ligada a las formulaciones de política exterior del gobierno de Raúl Alfonsín y, a nuestro entender, a las gestiones de Néstor y Cristina Kirchner. Dicho en otras palabras: liberalismo y alineamiento por una parte y desarrollismo y autonomía por la otra, son enfoques aún en pugna en la Argentina de nuestros días. (Pignatta, 2010).

En referencia a la creciente incidencia de los condicionantes internos en la PEA, cabe señalar que cada uno de los grandes ciclos ${ }^{2}$ de la política argentina en democracia se inició luego de una profunda crisis. A este respecto, la literatura especializada establece una vinculación entre las situaciones de crisis y la facilidad para innovar en el ámbito de las políticas públicas. Entre los mecanismos propios de esta vinculación, Palermo y Torres (1994:6) destacan que:

«el primero es aquel por el cual se refuerza el mandato de un nuevo liderazgo presidencial. La crisis tiene el efecto de desacreditar las posturas y las ideas de la administración anterior y predispone a la opinión pública a conceder a quienes acceden al gobierno una oportunidad para resolver la emergencia. Por otro lado, el estallido de la crisis hace cundir el temor por la suerte del orden público porque no solo los problemas económicos se agudizan sino que también suele asistirse a un alza de la conflictividad y a episodios de protesta violenta. A todo esto se agrega otro fenómeno que contribuye a crear un marco institucional más permeable a la implementación de reformas. Nos referimos al bien conocido sentido de urgencia que la crisis instala en la opinión pública, fortaleciendo la creencia de que la falta de iniciativas solo puede agravar las cosas; en esas circunstancias, 'tomar

Para analizar la relación entre democracia y política exterior utilizamos la idea de «ciclos» de la política argentina porque entendemos que desde 1983 existieron tres grandes momentos en los que se intentó proponer diseños de política externa y, algunos de ellos, abarcan a más de un gobierno: el ciclo alfonsinista, el ciclo Menem-Alianza UCR-FREPASO y el ciclo Duhalde- Kirchner. 
AnAbella Busso • Los vaivenes de la política exterior argentina re-democratizada...

una decisión se vuelve más importante que la manera cómo se la toma', esto es, los escrúpulos acerca de los procedimientos más apropiados para decidir que prevalecen en tiempos más normales dejan paso a una aceptación más conformista de las medidas extraordinarias utilizadas para conjurar la crisis»

Siguiendo ese razonamiento, cabe resaltarse que la llegada al gobierno del ex presidente Alfonsín se produjo tras un fuerte periodo de autoritarismo iniciado en 1976 y caracterizado por un alto nivel de violaciones de los derechos humanos y un marcado proceso de liberalización, desindustrialización y privatización de la economía argentina (con excepción de las producciones a cargo de las Fuerzas Armadas), con un fuerte endeudamiento externo en que el país, junto a Brasil y México, se ubicó como uno de los principales deudores mundiales. Además, la inflación anual era del $433,7 \%{ }^{3}$. A esta compleja y dramática herencia, debemos sumar la tendencia del gobierno militar argentino a resolver determinados asuntos internacionales a través de la guerra. En este marco se inscriben tanto el conflicto por el canal de Beagle con Chile -que estuvo a punto de conducir al enfrentamiento entre ambos países- como la derrota frente a Gran Bretaña en la guerra de Malvinas, lo que profundizó la desinserción internacional del país.

3 Este dato fue tomado de Thomas Bulner, The Economic History of Latin America Independence, Cambridge, citado por Rapoport (2010).
Por su parte, el arribo de Carlos Menem a la Casa Rosada, en julio de 1989 , se enmarcó en una profunda crisis económica y en un contexto hiperinflacionario donde el aumento de los precios alcanzó en ese año un $4.923,6 \%{ }^{4}$ con crecientes demandas sociales que condujeron a la entrega anticipada del poder por parte del gobierno radical.

Finalmente, el gobierno de Néstor Kirchner fue heredero de la crisis del 2001, considerada la más profunda de la historia argentina por sus múltiples consecuencias económicas, políticas, institucionales y sociales. En este sentido, la situación de default, la existencia de cuasi-monedas, el nivel de desempleo, la potenciación de los indicadores de pobreza, las dificultades para garantizar la gobernabilidad, el deterioro de la figura presidencial y el descreimiento de la sociedad en la política generaron una sensación de anomia generalizada que estaba presente en mayo de 2003 cuando el presidente asumió su cargo.

Si bien los análisis relativos a la calidad de la democracia marcan determinadas continuidades en los indicadores sobre la condición democrática en la Argentina desde 1983, a los fines de analizar la relación con la PEA nos interesa subrayar que en el país se dieron modificaciones en torno a los componentes democráticos que la sociedad y la clase política privilegiaron ante cada ciclo político.

4 Ibidem. 
Después de siete años de autoritarismo, frente a la llegada de un gobierno democrático el pueblo argentino se aferró a una idea de democracia más tradicional donde se subrayaban los componentes electoralistas y la defensa de los derechos civiles y políticos que habían sido totalmente vedados bajo el régimen militar. En este sentido, como afirma Garretón (2004:230) «la democracia [fue vista] como el régimen deseado y no subordinable a otras dimensiones». Es importante tener en cuenta que dicha valoración y percepción de la democracia no solo provino de la sociedad argentina sino que fue compartida por la clase política y se encarnó en la famosa frase de Raúl Alfonsín, en que se afirmaba que «con la democracia no solo se vota, sino que también se come, se educa y se cura» (Alfonsín, 1983).

En la década de los años noventa, coincidente con la gestión de Carlos Menem, la percepción argentina sobre la democracia se vio afectada tanto por cuestiones internas como internacionales. Desde el punto de vista interno, la sociedad había experimentado que la democracia era un régimen político altamente positivo en términos de garantía de los derechos políticos y civiles y que, además, había permitido resguardar al sistema político de las persistentes amenazas de golpe militar. Sin embargo, estos atributos del régimen democrático no se trasladaban automáticamente a la consolidación del desarrollo nacional y a la satisfacción de las necesidades económicas. La experiencia hiperinflacionaria marcó a la sociedad argentina, que había confirmado que la expresión de Alfonsín quedó a mitad de camino, ya que con la democracia se pudo votar pero no necesariamente comer, educar y curar.

Por otro lado, desde un punto de vista sistémico, se consolidan las perspectivas neoliberales instalando a nivel mundial el debate Estado versus Mercado, donde el primero perdería espacio frente al segundo. Esto significó que, a lo largo de estos años, la política se supeditara al mercado y las sociedades nacionales tendieran más a buscar la satisfacción de necesidades económicas que a incrementar la participación política. Fue así que los politólogos en los años noventa pondrían su atención en temas relacionados con la calidad y el tipo de democracia, apareciendo lo que David Collier y Stephen Levitsky denominaron «democracias con adjetivos» en que surgieron expresiones como «democracia delegativa», "tutelada» y «de baja intensidad» (Pignatta, 2011). Otras visiones ligaban la consolidación de la democracia al efecto desmovilizador del neoliberalismo (Whitehead, 1993). Dicho en otras palabras, y trasladando el análisis al caso argentino, durante la década de 1990 la sociedad argentina, como muchas otras, no redujo su valoración de los aspectos formales de la democracia pero sí sus niveles de participación política y transitó por una etapa en que los intereses individuales o sectoriales estuvieron por encima de los intereses colectivos. 
ANABella Busso • Los vaivenes de la política exterior argentina re-democratizada...

Tras la crisis del 2001, en contraposición a la apatía política de la década precedente, se produjo un estallido de movilización social y las demandas colectivas incluyeron no solo reclamos económicos sino también una fuerte crítica a la clase dirigente y un pedido de mejor representación política. En otras palabras, la sociedad argentina reclamaba una redefinición del vínculo Estado-sociedad. A medida que el gobierno kirchnerista fue atendiendo los problemas más urgentes e identificó a las políticas económicas neoliberales y la consecuente ausencia del Estado como causas principales de la crisis, se comenzó a reivindicar la política como el instrumento más adecuado para resolver los problemas nacionales.

Consecuentemente, algunas acciones del gobierno, como otorgarle un rol protagónico al Estado en la orientación de la economía nacional; confrontar fuertemente con actores externos como el FMI, los tenedores de bonos y las empresas extranjeras radicadas en el país, llevaron a una recuperación de la figura presidencial y a un incremento del poder en manos del Ejecutivo. Esto no generó inquietudes en la población sobre las condiciones democráticas en Argentina sino, por el contrario, logró un consenso social significativo. Sin embargo, cuando la gestión salió de la urgencia y la consolidación de las políticas iniciadas involucró los intereses de actores internos importantes (medios de comunicación, sector agrario, importadores, etc.) la discusión sobre la calidad de la democracia resurgió y se focalizó en qué componentes del concepto de democracia se deben privilegiar, si aquellos basados en la institucionalidad republicana y liberal o aquellos basados en la soberanía popular.

Este debate no es exclusivo de la Argentina sino que, con menor o mayor intensidad, abarca a otros países latinoamericanos que atravesaron situaciones de crisis ligadas a las consecuencias negativas de la etapa neoliberal y, también, a algunos países europeos altamente afectados por la crisis del 2008. Así como la academia en los años ochenta abordó la transición democrática y la idea de una "democracia defensiva» y en los años noventa aludió a la «calidad» de la democracia, en el siglo XXI la discusión discurre, sin dejar de lado las reflexiones anteriores, en torno a la posibilidad de aceptar o no distintas articulaciones entre los componentes de una democracia. En este sentido, Chantal Mouffe (2012) realiza un aporte interesante a esta discusión ya que sostiene que "Hay que aceptar que va a haber distintas formas de democracia, que corresponden a su adscripción en distintos contextos históricos». Por esta razón, reivindica algunas experiencias democráticas latinoamericanas del siglo XXI en las que no observa un rechazo al modelo liberal-democrático occidental, sino una rearticulación de esas tradiciones pero «con predominio de la soberanía popular».

En Estados Unidos y en Europa, el elemento liberal de las democracias se ha vuelto absolutamente dominante, mientras el elemento democrático, el 
de la igualdad y la soberanía popular, ha sido subordinado y, en algunos casos, eliminado. La idea en esos países sobre qué es la democracia involucra el Estado de derecho, respeto de los derechos del hombre, separación de poderes, pero no se hace referencia a la soberanía popular y la igualdad. Ese predominio del componente liberal es lo que están poniendo en cuestión algunos gobiernos latinoamericanos, que han ubicado al elemento democrático como elemento principal. El componente liberal no ha sido eliminado, pero está subordinado. Por eso es que en Europa y Estados Unidos no se entienden algunas experiencias latinoamericanas y hay hostilidad hacia ellas, no solo desde la derecha, sino también desde la izquierda, que no acepta esta nueva rearticulación con predominio de la soberanía popular (Mouffe: 2012).

\section{IMPACTOS DE LOS}

CONDICIONANTES INTERNOS EN la PE de Alfonsín, Menem y Néstor y Cristina Kirchner

Este conjunto de causas internas -diferencias en torno al modelo de desarrollo, crisis recurrentes y distintas maneras de entender la democraciaimpactó en las principales líneas de PE de los gobiernos democráticos en tanto debilitó la cohesión interna que, como afirma Ferrer (2010), cualquier Estado necesita para alimentar su soberanía y poder negociar cuestiones políticas y económicas con otros actores internacionales.

Un repaso acotado por la PE alfonsinista nos permite vislumbrar cómo la acuciante situación interna del país en 1983 contribuyó a la selección de las cuestiones que participarían del diseño de la PE. Entre sus principales objetivos se destacaban la priorización de los temas de agenda latinoamericana y la recomposición de los vínculos con Estados Unidos y Europa, fuertemente deteriorados como consecuencia de la guerra de Malvinas. Desde el punto de vista económico, se buscaba la disminución del peso de la deuda en la estructura económica argentina, la integración económica subregional y la cooperación Sur-Sur con la expectativa de que esto contribuyera a reactivar la economía nacional y controlar la inflación. Desde la perspectiva estratégicomilitar, no solo se proponía impugnar el orden bipolar en general sino también las tensiones derivadas de la llamada «nueva guerra fría» vigente en los años de Reagan y Thatcher, a la vez que se proponía un compromiso con la no-proliferación. En líneas generales, Alfonsín planteó una política exterior que pretendía lograr la reinserción internacional de la Argentina como un país occidental y no alineado, presupuesto este último que implicaba una acción externa de perfil autonómico.

La opción inicial por un modelo de desarrollo de tradición desarrollista representada en la elección de Bernardo Grinspun como Ministro de Economía, afrontó presiones internacionales 
AnAbella Busso • Los vaivenes de la política exterior argentina re-democratizada...

ligadas al alto nivel de endeudamiento externo y presiones internas vinculadas a los problemas inflacionarios, que actuarían como un límite para su concreción. En este marco enfrentó a la patria financiera con los grupos concentrados de la economía, como también a los organismos financieros internacionales (Canteros, 2012). Así, el rol activo de Argentina durante 1984 en la creación del Consenso de Cartagena con el objetivo de constituir un club de deudores latinoamericanos que politizara el tratamiento del tema y optimizara los mecanismos de negociación internacional con los acreedores se vio rápidamente truncado. La oposición de la administración Reagan, la banca privada de capitales y la falta de apoyo de los países europeos influyeron fuertemente para que los Estados de la región negociasen individualmente con el Fondo Monetario Internacional y se evitara el no pago de la deuda que llevaría a la quiebra a varios bancos estadounidenses. Esta situación finalizó con la renuncia de Grinspun. Su remplazo fue Juan Vital Sourrouille y un equipo técnico con mayor consenso externo, que tuvieron la misión de contener una inflación por entonces del 30\% mensual y buscar un mecanismo de negociación con los bancos acreedores. De aquí nace el Plan Austral.

Este cambio en la dirección del tratamiento de la deuda generó el denominado "giro realista» de la política exterior alfonsinista que no solo implicó una mayor jerarquización de Estados Unidos en la agenda externa, sino también la consolidación de las convergencias entre ambos países por sobre las divergencias. Además, dicho giro incluyó la toma de conciencia por parte del gobierno de las limitaciones del apoyo europeo. El supuesto alfonsinista sobre un sustento europeo amplio basado en coincidencias ideológicas socialdemócratas y en la comunión en torno a la democracia, se desvaneció. Finalmente, la búsqueda de una integración regional dejó ser un objetivo general para convertirse en un proceso de integración selectiva con Brasil. La suma de estos hechos muestra el surgimiento de límites a la visión autonomista del gobierno.

Las influencias externas mencionadas más arriba tenían un fuerte impacto por su peso específico, pero se potenciaban porque la situación política y económica interna no lograba alejarse de la crisis que había heredado. En este marco se destaca la oposición de los sindicatos a las políticas económicas del gobierno a lo largo de toda la gestión del partido radical. Los doce paros generales que la Confederación General del Trabajo realizó durante esos años se basaron en los problemas salariales ligados a los altos índices de inflación y a la propuesta de ley para modificar el sistema sindical que el gobierno había presentado en los primeros meses de gestión, que no logró aprobar pero abrió una distancia entre las representaciones obreras y Alfonsín que no logró cerrarse.

Los desafíos directos a la estabilidad institucional provinieron de los milita- 
res quienes participaron en múltiples levantamientos que mantuvieron en permanente vilo al gobierno. La relación de Alfonsín con los militares fue permeada a lo largo de toda su gestión por la temática de los derechos humanos, enarbolada por el gobierno vía los juicios a las Juntas Militares, que generó demoras y acotó la posibilidad de avanzar en el diseño de una política de defensa para la era de la redemocratización. Las concesiones otorgadas a los militares a través de las leyes de Obediencia Debida y Punto Final generaron la oposición de los grupos defensores de los derechos humanos quienes mantuvieron el tema en agenda hasta el gobierno de Kirchner, cuando la Corte Suprema reconoció la inconstitucionalidad de esas leyes. Sin embargo, es importante subrayar que antes de los intentos desestabilizadores o de golpe de estado provenientes de las Fuerzas Armadas, el gobierno contó con apoyos provenientes de la participación popular, los sectores de oposición política e, inclusive, las grandes corporaciones económicas que evaluaban como más conveniente la continuidad democrática. Esta tendencia también se hizo presente en el alto porcentaje de apoyo al plebiscito sobre el canal de Beagle convocado por el gobierno para aceptar o no los resultados de la mediación papal.

En referencia a las acciones de los actores económicos internosy su incidencia directa o indirecta en la PE hay que realizar algunas distinciones. El sector agrícola tuvo, al igual que el sindicalismo, una relación compleja con Alfonsín a lo largo de todo el mandato. Las diferencias principales se originaban en las críticas hacia las políticas de subsidio al sector industrial en contraposición a las retenciones realizadas a las exportaciones agrícolas. Una dirección similar se da con el sector financiero que presionaba, desde adentro y desde afuera, para que Argentina no se declarase en cesación de pagos.

Los vínculos con el sector empresarial fueron cambiantes. Cuando en 1985 se lanza el Plan Austral y se logra bajar abruptamente los índices inflacionarios mediante un mix de medidas ortodoxas y heterodoxas, el equipo económico negocia los contenidos del plan con autoridades externas como la Reserva Federal, el Departamento del Tesoro y el Fondo Monetario Internacional (De Pablo, 2009:28) e, internamente, lo hace con las grandes empresas nacionales conocidas como «los capitanes de la Industria» y un grupo de banqueros. Pasada la instancia exitosa con la disminución de la inflación, la situación económica tendió a agravarse y el gobierno presentó en agosto de 1988 un plan alternativo, conocido como «Primavera», que contó con una alianza distinta de la anterior en que participaba la Unión Industrial Argentina y cierto acercamiento con la Sociedad Rural. Lo cierto es que la situación económica volvió a empeorar y tanto los capitanes de la Industria, como los banqueros y la Sociedad Rural que acompañaron por un tiempo al gobierno, llevaron adelante el 6 de 
ANABella Busso • Los vaivenes de la política exterior argentina re-democratizada...

febrero de 1989 un golpe de mercado que aceleró el estallido hiperinflacionario, incrementó la fuga de capitales, fomentó el escenario creciente de ingobernabilidad (manifestaciones, saqueos a supermercados y centros comerciales, desabastecimiento), generando la entrega del gobierno en forma abrupta y anticipada.

$\mathrm{Al}$ arribar Menem a la presidencia, el estallido de la hiperinflación heredada del alfonsinismo que, como dijimos llegó a 4.923,6\% en 1989 creó, como afirman Palermo y Torres (1994:6), «(...) una incontrovertible 'situación de crisis' que puso a su disposición un espacio político de envergadura hasta entonces desconocida para dar respuestas a la emergencia en que se hallaba el país».

La campaña política que condujo al triunfo de Carlos Menem se enmarcó en el descontento social e incluyó planteos coincidentes con la tradición peronista anunciando una revolución productiva y un "salariazo». Sin embargo, en el periodo transcurrido entre la elección y la asunción anticipada del poder, haciendo uso del espacio político abierto por la crisis, se vislumbraron los cambios que se iban a producir en tanto las alianzas con otros partidos políticos y actores económicos giraron hacia la centroderecha anunciando que su Ministro de Economía sería Miguel Ángel Roig, ex gerente de Bunge y Born, mientras que otros miembros de su gabinete provendrían de la Unión de Centro Democrático, un partido emblemático de la derecha argentina.
De acuerdo con declaraciones de los funcionarios de entonces, esta decisión se basó en las percepciones de la administración menemista sobre los cambios operados a nivel mundial y en la determinación de implementar una reforma estructural en la economía argentina y convertirla en el eje sobre el cual debían articularse las demás políticas públicas, entre ellas la PE. En este sentido, la percepción del sistema internacional estaba ligada a un escenario de posguerra fría y consolidación del proceso de globalización, caracterizado por la caída de los socialismos reales, el ascenso de los Estados Unidos, Europa y Japón, el inicio de un crecimiento significativo de las economías asiáticas como las de China y los NIC y la primacía del paradigma de economía de mercado y defensa de la democracia liberal. Consecuentemente, se evaluaba como requisito necesario para que Argentina mejorase su inserción internacional vivir en "sintonía con la época». Esto implicaba una PE caracterizada como occidental pero fundamentalmente, ligada a una práctica de alineamiento con los Estados Unidos, identificado como el país más importante del planeta.

En esta dirección, el presidente Menem afirmaba:

\section{(...) el distanciamiento [entre} Argentina y Estados Unidos] produjo resultados negativos para ambas naciones. Hoy ante un mundo donde la integración y la cooperación son los valores motores de la conducta internacional, tenemos la sensación de que los resquemores entre los Estados Unidos y América Latina, y la 
Argentina en este caso en particular, han sido demasiado largos y estériles. No me queda la menor duda de que debemos superarlos porque siento que en todos los ordenes internacionales hoy se impone acortar distancias y dejar a atrás aquello que no contribuya a mejorarlas» (Menem, 1990: 10).

Entre algunos de los acontecimientos y decisiones más destacados de la política de alineamiento pueden señalarse el envío de una fuerza naval y tropas a la primera guerra del Golfo, el retiro de Argentina del Movimiento de no Alineados, la modificación del perfil del voto argentino en las Naciones Unidas, la adhesión a los regímenes de control y no proliferación, el abandono de la política misilística encarnada en el Cóndor II, el acceso a la condición de aliado extra OTAN, la firma de acuerdos bilaterales de garantía de inversión y la adhesión al CIADI. Dicho alineamiento con la potencia hegemónica se articuló con una política activa hacia la región. Algunos componentes de esa política trasladaban parte de los acuerdos con Estados Unidos al tratamiento de temas hemisféricos en la Organización de los Estados Americanos, mientras que otros presentaban contenidos propiamente regionales en que se destacan los vínculos con algunos países vecinos 5 .

5 En cuanto a los temas hemisféricos Argentina apoyó todas las iniciativas en la OEA para la defensa de la democracia y participó de las Conferencias Especiales para la generación de medidas de confianza propias de un sistema de seguridad cooperativo. Por otra parte, en el ámbito re-
Desde el punto de vista interno, y en estrecha relación con el modelo de desarrollo, se propuso una reforma económica neoliberal que profundizó la estrategia de desindustrialización, privatización de empresas públicas y apertura de mercados que se había iniciado con el golpe militar de 1976, y que dejaba de lado cualquier posibilidad de recuperar una tradición desarrollista ligada al modelo de industrialización por sustitución de importaciones. Esto, como ya anticipamos, implicó una redefinición de las alianzas tradicionales del peronismo que, en este caso, se orientó hacia las empresas extranjeras ligadas al sector «servicios» que participaron del proceso de privatizaciones, a las grandes empresas argentinas y a los sectores agropecuarios más poderosos, produciendo un paulatino distanciamiento con los sectores productivos vinculados a la pequeña y mediana empresa. Por otra parte, si bien la Confederación General del Trabajo terminó dividiéndose en dos grupos a lo largo de la década de 1990, en líneas generales y en función de su tradición peronista, los sindicatos acompañaron el proceso de reforma.

gional, se solucionaron los 23 conflictos limítrofes pendientes con Chile y el país tuvo un rol protagónico, junto con Brasil, en la creación del MERCOSUR a la que se sumaron Uruguay y Paraguay. En este contexto, a pesar del alineamiento, desde 1994 cuando el Presidente Clinton propuso la creación del ALCA, Argentina articuló su política con Brasil para fijar una posición en común. 
ANABella Busso • Los vaivenes de la política exterior argentina re-democratizada...

En relación con las Fuerzas Armadas, durante la campaña electoral algunos sectores militares percibían al cambio de gobierno como una posibilidad de mejorar los vínculos con el poder político. En correlación con esta idea, Carlos Menem decretó, en octubre de 1989, una serie de indultos que incluían a unas 300 personas provenientes tanto de las Fuerzas Armadas como de los grupos guerrilleros de la década de 1970. Sin embargo, el 3 de diciembre de 1990 debió enfrentar un nuevo desafío militar del sector "Carapintada» que ocupó, entre otros, el Edificio Libertador y las instalaciones del Regimiento I de Infantería. Las Fuerzas Armadas sofocaron violentamente la rebelión poniendo fin a la situación de levantamientos militares recurrentes desde la recuperación de la democracia. Acto seguido, sobre finales de diciembre de 1990 y con el argumento de la «reconciliación y pacificación nacional», Menem decidió conceder una segunda tanda de indultos a 1200 personas que incluyeron a los miembros de las Juntas Militares -condenados en el juicio de 1985- al Ministro de Economía Martínez de Hoz y a los líderes de las organizaciones guerrilleras. Si bien esta decisión pareció estabilizar el vínculo con los militares, abrió una herida con los organismos de derechos humanos y con los sectores por ellos representados que no se saldaría hasta el gobierno de Néstor Kirchner.

La concepción de democracia que predominó a lo largo de la década de 1990 incluyó, como dijimos, una valoración positiva de la democracia formal, pero redujo notablemente los niveles de participación política de la sociedad argentina. Entre los argumentos académicos sobre las causas de este fenómeno se destacan dos, que a pesar de sus diferencias coinciden en subrayar la disminución y el deterioro de la participación política. En términos de Whitehead, lo que se dio en esos años en América Latina, es un fenómeno de «democracia por default». En este marco el autor establece una relación entre despolitización y hegemonía neoliberal, cuyo principal beneficio es evitar la «inestabilidad populista». Así, el neoliberalismo podía proveer una vía de consolidación democrática donde los políticos debían mantener altos niveles de despolitización mientras avanzaban en las reformas de mercado. Obviamente, este análisis se ve obligado a reconocer que la democracia que se consolida por este medio carece de muchos de los elementos usualmente vinculados con la idea de democracia liberal (alto grado de participación; posibilidad de elección entre alternativas políticas, derechos ciudadanos extendidos) (Whitehead, 1993, 314 a 325; citado por Peruzzotti, 1998). Por su parte, O’Donnell (1994) sostiene que la estabilidad política de los años noventa es el resultado de la combinación de estilos políticos populistas en un contexto sociopolítico post-populista. El producto de dicha combinación es un régimen híbrido basado en la delegación política y no en una efectiva participación o representación. En este 
contexto, al menos siete de los diez años de Menen en el poder se enfrentaron con una sociedad con poco nivel de participación y opinión sobre las políticas públicas. Si bien el tema del alineamiento con Estados Unidos era una cuestión abordada críticamente por algunos sectores académicos y de oposición, por considerarlo un dato histórico desacoplado de la tradición de la PEA en general y de los gobiernos peronistas en particular, no se logró generar una barrera de envergadura.

Los cambios económicos implementados durante el primer año del gobierno de Menem, si bien siempre buscaron reposarse en la alianza con los sectores más liberales, no lograron solucionar el problema más acuciante de la Argentina que era la situación inflacionaria. Después de la corta gestión Roig y de su sucesor Antonio Erman González, Argentina terminará enfrentando un nuevo escenario hiperinflacionario que llevará desde la Cancillería hacia el Ministerio de Economía a Domingo Cavallo en 1991, quien impulsará la Ley de Convertibilidad ${ }^{6}$ mediante la cual se logró detener el proceso inflacionario a lo largo del resto de la gestión. Sin embargo, este modelo económico irá incrementando de forma permanente la concentración económica en los secto-

Esta Ley implementó un nuevo régimen cambiario estableciendo en primera instancia que 10.000 australes equivalían a un dólar estadounidense. Posteriormente, en 1992, y habiendo cambiado la moneda, la equivalencia pasó a ser 1 peso argentino igual a 1 dólar. res financieros y de servicios y, al mismo tiempo, los niveles de desocupación y desindustrialización.

La experiencia tan negativa que los estallidos hiperinflacionarios generaron en la sociedad argentina hizo que la política de convertibilidad, a pesar de sus efectos económicos y sociales negativos a largo plazo, se convirtiese en una estrategia con apoyo social que futuros gobiernos como el de Fernando De la Rúa no se atrevieron a abandonar. Esta situación, sumada a las dificultades políticas de la Alianza UCR-FREPASO que ganó las elecciones en 1999, cimentaron las bases de una nueva crisis que estalló en diciembre de 2001 y que se convertiría en una de las debacles más profundas de la historia argentina, con fuerte impacto en la evolución política, económica y las formas de participación política.

Consecuentemente, para enmarcar el análisis de la acción externa argentina en los tiempos de Néstor Kirchner, no podemos olvidar el impacto heredado de la profunda crisis de 2001 que generó un «colapso estatal». La situación de default, el nivel de desempleo, la potenciación de los indicadores de pobreza $(53 \%$ de la población bajo el nivel de pobreza), las dificultades para garantizar la gobernabilidad, el deterioro de la figura presidencial y el descreimiento de la sociedad en la política generaron una sensación de anomía que estaba totalmente presente en mayo de 2003 cuando el presidente asumió su cargo. Ante esta situación, la sociedad civil mantuvo los reclamos de 
ANABella Busso • Los vaivenes de la política exterior argentina re-democratizada...

cambios planteados ante la dirigencia desde 2001 para que se recompusiesen los mecanismos de representatividad, se mejorasen las condiciones socioeconómicas del país y se optimizasen los resultados de las políticas públicas. Como símbolo de la época, el Presidente Kirchner solía afirmar que pensaba en términos de minutos para enfatizar lo apremiante que resultaba la atención de la coyuntura y las limitaciones de entonces, para planificar estratégicamente el mediano y largo plazo.

Ese contexto caracterizado por una agenda interna compleja y apremiante tuvo un impacto importante en la PE en tanto esta fue pensada como un instrumento que debía aportar a la solución de los problemas internos. Expresiones del Presidente tales como "pensar el mundo en argentino", o que la agenda externa debía «abarcar los temas de la gente» hacen referencia expresa a esta tendencia.

En esa dirección, Lafer (2002:21) afirma que traducir necesidades internas en posibilidades externas para ampliar el control de una sociedad sobre su destino es la tarea de la PE como política pública y esto implica evaluar los problemas, necesidades e intereses de esa sociedad desde una visión que incluya el bien común de la colectividad nacional, lo cual no es una tarea simple. Como venimos sosteniendo, en la Argentina re-democratizada han perdurado las pugnas en torno a las propuestas de modelo de desarrollo y sus respectivos alternativas de PE (industrialización/autonomía; neoliberalismo/alineamiento) lo cual ha dificultado la búsqueda de intereses colectivos. Este debate se manifestó con distinta intensidad a lo largo de la última década, siendo más notorio en épocas de Cristina Fernández que en los tiempos de Néstor Kirchner.

El gobierno de Kirchner optó por una visión autonomista- industrialista basada en el mercado interno y evaluó que para poder pensar las necesidades e intereses locales y lograr el apoyo de distintos sectores sociales era necesario consolidar el liderazgo presidencial, incrementar la gobernabilidad y dar claros signos de cambio en los criterios para afrontar y salir de la crisis económico-social que se vivía en ese momento. Para llevar adelante esta tarea resultaba imprescindible reinstalar la «centralidad de la política» como el instrumento adecuado para la solución de las dificultades nacionales. Esta tendencia fue bastante generalizada en la región latinoamericana en la primera década del siglo XXI y, según Garretón (2006), no devino de la desaparición o superación de la agenda económica, sino de la persistencia de tres grandes problemas que deben ser resueltos desde la política: «el papel del Estado como dirigente del proceso de desarrollo y agente principal de la inserción en la globalización, la superación de las desigualdades y la transformación productiva que significa tanto la efectiva incorporación de la región a la sociedad del conocimiento como la generación de empleos decentes». 
En este contexto, Kirchner tuvo participación directa en el diseño de la política económica nacional e internacional y en algunos asuntos de la PE, mientras que internamente buscó sustentar el liderazgo en el creciente apoyo de la opinión pública a través del cual también fue consolidando su poder político. En concordancia con estas ideas, en los primeros años de gestión la PE hacia Estados Unidos, España (de donde provenían la mayoría de empresas de servicios públicos) y los organismos multilaterales de crédito fueron un resorte exclusivo del Presidente. A esta participación presidencial se agregó un estilo discursivo que se caracterizó por ser frontal, destacar las necesidades de la población argentina y recuperar conceptos como dignidad nacional e intereses nacionales, entre otros. Estos contenidos fueron acompañados por una fuerte crítica a los actores internos (especialmente el gobierno de Menem) e internacionales tales como el Fondo Monetario Internacional, el Banco Mundial, el sector financiero transnacional, las empresas multinacionales que habían participado de las privatizaciones e, inclusive, algunos gobiernos de los países centrales a los que se les atribuyó responsabilidades en la crisis económica argentina y las dificultades para la renegociación de la deuda.

Simultáneamente, la crisis socioeconómica interna estuvo directamente ligada al proceso de renegociación de la deuda. Este apareció como un tema central al cual se subsumieron otras dimensiones de la PE. La estrategia del gobierno en este ámbito también articuló una fuerte presencia presidencial y un discurso frontal, pero contó con el soporte técnico del Ministerio de Economía en la figura de Roberto Lavagna. Dicha estrategia se basó en establecer objetivos de máxima que no serían modificados sustancialmente después de haber sido anunciados públicamente. La diferencia central con los '90 se basó en subrayar que, a pesar de sus debilidades, la Argentina aún podía decir que no en un proceso de negociación y, además, se sostuvo permanentemente el supuesto de que "sin crecimiento con inclusión social no hay capacidad de pago durable en el tiempo» (Lavagna, 2005). En conexión con este tema y pasados algunos meses desde la asunción del mando, la dimensión comercial de la PE se convertiría en una de los principales objetivos de la acción externa de nuestro país. Kirchner entendía que el superávit comercial era un elemento central, junto al equilibrio fiscal y la recuperación de las reservas, para apuntalar un proceso de reindustrialización y generación de empleo en Argentina y garantizar la política de desendeudamiento. Además, siempre se sostuvo que Argentina apostaba al multilateralismo y que el marco internacional de referencia de nuestro país era Latinoamérica en general y Sudamérica en particular. En este contexto las relaciones con Brasil y Venezuela fueron muy significativas. Aunque problemas de agenda doméstica afectaron los contactos con Chile por la crisis del gas y con Uruguay por 
AnAbella Busso • Los vaivenes de la política exterior argentina re-democratizada...

la crisis de las pasteras, las relaciones recuperaron posteriormente cierto equilibrio, pero no alcanzaron los niveles anteriores de confianza.

Si bien la gestión de Néstor Kirchner enfrentó severos condicionantes internos, es necesario subrayar que los actores económicos en general (industria, agro, finanzas) que venían sufriendo los efectos de estar subsumidos en la crisis acompañaron, en líneas generales, al gobierno. Obviamente, el reordenamiento de la economía y el inicio de una etapa de recuperación, beneficiaron significativamente a todos los sectores. Por otra parte, hasta el final de su gestión, y en función de los objetivos que se habían establecido, Kirchner concentró los aspectos más confrontativos de la acción diplomática y económica en actores externos, lo que no afectaba de lleno los intereses locales y contaba con apoyo social. Por otra parte, la reorientación de la política económica y la generación de empleo consolidaron el apoyo de los sectores sindicales.

Desde el punto de vista de la ciudadanía y su participación democrática también se produjo una sinergia positiva. La Argentina de entonces se caracterizaba por un nivel de demanda y movilización social importante y caótico. Sin embargo, las autoridades dejaron de lado toda posibilidad de represión en búsqueda de un mayor grado de estabilidad que no fomentara más enfrentamientos, especialmente con agentes de seguridad estatal, sino que proviniese de las mejoras económicas y sociales y de los equilibrios establecidos por la misma sociedad en referencia a lo que debía o no permitirse en el marco de las demandas sociales. Por otra parte, la idea de que la política y, consecuentemente, la participación debían ser reivindicadas como una práctica permanente fue adquiriendo cada vez más fuerza. De esta manera, se inicia un cambio en la forma de entender y poner en funcionamiento la democracia, que distancia las concepciones actuales de los años noventa. Finalmente, la renovación de la Corte Suprema de Justicia con jueces probos y no adictos fue muy bien vista por la sociedad como parte de una democracia renovada.

Durante esta etapa, las relaciones con las Fuerzas Armadas se caracterizaron por un tipo de tensión que no se vincula con la posibilidad de que los uniformados produzcan amenazas de inestabilidad institucional sino con la política de derechos humanos del gobierno. En este período, a diferencia de la etapa de Alfonsín y Menen, se declararon inconstitucionales las leyes de Obediencia Debida y Punto Final y se anularon los indultos. En consecuencia, se iniciaron a lo largo del país los juicios a todos aquellos militares acusados de delitos de lesa humanidad acontecidos durante el último gobierno militar. La política de verdad y justicia produjo efectos dispares. Por un lado deterioró el apoyo de los militares a la gestión en tanto entendían que la cuestión de los derechos humanos no involucraba a las nuevas generaciones de oficiales y que, sin embargo, estos continuaban siendo 
observados siempre a través del mismo prisma. Por otra parte, esta política recibió el apoyo de varios organismos de derechos humanos (entre los que se destacan Madres y Abuelas de Plaza de Mayo), de diversas organizaciones sociales y de una parte importante de la sociedad civil. De hecho el «issue» derechos humanos se convirtió en un eje de la PE.

El gobierno de Cristina enfrentó situaciones diferentes. Heredera de una gestión exitosa, la tarea pendiente era la consolidación del modelo iniciado por Néstor Kirchner. Esto implicaba, entre otras cuestiones, cuidar e incrementar la generación de empleo, reforzar el proceso de industrialización, atender las repercusiones internacionales y nacionales de los acreedores que habían quedado afuera de la renegociación de la deuda y fortalecer una PE autonómica y pro-latinoamericana. Además, en su campaña electoral Cristina había planteado un perfil más internacionalista que el de Néstor y la búsqueda de una mayor y mejor institucionalidad democrática a nivel interno.

Sin embargo, una serie de cuestiones entre las que se destacan la complicación del escenario interno a partir del conflicto con el campo; los cambios producidos en la relación entre el gobierno y la sociedad y entre el gobierno y los medios de comunicación hegemónicos; el impacto de la crisis financiera internacional desatada en 2008; y el fallecimiento del ex presidente Kirchner, van a afectar de manera constante estas expectativas. En este marco, el gobierno de Cristina enfrenta de manera regular variaciones en la estructura de alianzas político-económicas en función de las disputas ideológicas y los intereses en torno al modelo de desarrollo; una ampliación del debate sobre qué tipo de democracia hay que defender y un conjunto de condicionalidades domésticas ligado a las variaciones del vínculo entre el gobierno y la sociedad. Todo esto tiene impacto en la PE.

Estos hechos y tendencias adquirieron una dinámica especial a partir del conflicto con el campo de 2008, cuando Cristina transitaba su primer año de gestión. Entre sus consecuencias, podemos señalar que el tema concentró por meses toda la atención del gobierno obligándolo, en ocasiones, a no atender la agenda internacional, como cuando la presidenta suspendió su visita oficial a China por no poder confiar en el Vicepresidente, Julio Cobos, para asumir transitoriamente la conducción de la Nación, ya que este había votado a favor de los reclamos planteados por las organizaciones empresarias que representan al sector agrícola-ganadero.

Consecuentemente, el conflicto produce la primera redefinición de las alianzas en tanto no solo genera un deterioro de los vínculos con los grandes productores agropecuarios agrupados en la Sociedad Rural y Confederaciones Rurales Argentinas, sino también con los medianos y pequeños productores agrupados en la Federación Agraria Argentina, quienes habían sido actores que apoyaron la gestión de Néstor 
ANABella Busso • Los vaivenes de la política exterior argentina re-democratizada...

Kirchner y fueron beneficiados por las políticas gubernamentales.

Por otra parte, la conflictividad alteró negativamente los vínculos entre el gobierno y la sociedad en tanto el conflicto se extendió en términos de opinión pública hacia los sectores medios urbanos que se posicionaron a favor del campo y contra la gestión de Cristina, apareciendo una clase media en permanente situación de reclamo sobre cuestiones como más seguridad, menos inflación, mejor institucionalidad, menos confrontación, entre otras.

Sin embargo, lo más impactante del conflicto fue su efecto catalizador en el enfrentamiento de los medios de comunicación hegemónicos, especialmente el Grupo Clarín, con el gobierno. Desde 2008, esos medios comenzaron a presentar en forma permanente ante la sociedad local y mundial una Argentina caótica, insegura, mal administrada, con un gobierno autoritario y una PE confrontativa que se acercaba a Venezuela y se alejaba de los gobiernos más exitosos de la región. Obviamente, el quebranto en la relación del gobierno con los medios hegemónicos y los sectores medios se reflejó en los resultados de las elecciones parlamentarias de 2009, que le dieron el triunfo a la oposición.

A modo comparativo, creemos conveniente destacar que el apoyo social a la confrontación con otros actores internacionales, como el Fondo Monetario Internacional, el Banco Mundial, las empresas multinacionales, etc. que caracterizó al gobierno de Néstor Kirchner en el proceso de renegociación de la deuda, no solo no se trasladó a la gestión de Cristina cuando la confrontación se dio con actores locales -en este caso el campo- donde el resultado fue una polarización de las posturas, sino que, inversamente, esta estrategia comenzó a ser claramente rechazada como instrumento de PE por quienes se oponen al gobierno y utilizan los adjetivos inconsistente, cambiante y confrontativa para referirse a la acción externa de Argentina. En este sentido, la reacción social y mediática fue menos permisiva con Cristina que con el ex presidente.

Sin embargo, este contexto interno negativo fue superado por la presidenta por cuestiones de distinta índole como la capacidad de administrar exitosamente los efectos locales de la crisis financiera desatada en 2008, la habilidad para obtener aprobaciones parlamentarias antes que se produjera la asunción de los nuevos legisladores y la incapacidad de la oposición política de unirse y presentar propuestas alternativas. Posteriormente, la reacción social ante la muerte del ex Presidente puso de manifiesto que un número significativo de argentinos acordaban con las directrices elegidas por el kirchnerismo para conducir los asuntos nacionales tanto a nivel interno como internacional. Esta tendencia se mantuvo sin mayores dificultades hasta las elecciones de 2011 que le dieron el triunfo a Cristina para su segundo mandato con un $54 \%$ de los votos. El dato discordante de esta etapa es la redefinición de la estructura de alianzas con los sindicatos. El titu- 
lar de la Confederación General del Trabajo, Hugo Moyano, se distancia del gobierno generando una división de las asociaciones gremiales entre las opositoras y las oficialistas. El quiebre del sector sindical constituye también una diferencia entre la etapa de Cristina y la de Néstor Kirchner.

Las dificultades económicas evidenciadas a partir de 2012 (creciente déficit fiscal; bajo nivel de inversiones; dificultades para mantener el superávit comercial; disminución de las reservas; escases de divisas e inflación) comenzaron a deteriorar el triunfo de Cristina de 2011 y exacerbaron las tensiones preexistentes entre el gobierno y los distintos sectores opositores, permeando el proceso de elecciones parlamentarias durante 2013. En este contexto de fuertes diferencias y condicionalidades internas, se vuelve a discutir el modelo de desarrollo, el perfil de la inserción internacional que Argentina necesita y la concepción de democracia que se debe defender, cuestiones que, sin duda continuarán impactando la PEA. De hecho las medidas restrictivas al comercio aplicadas por el gobierno argentino han generado distintos frentes de conflicto y conllevaron la necesidad de armar misiones diplomáticas hacia los países vecinos a los efectos de que estas decisiones no dañen los vínculos bilaterales.

Desde el conflicto del campo, sectores cercanos al gobierno comenzaron a señalar la existencia de acciones destituyentes provenientes de los medios de comunicación, el sector agrario, empresas multinacionales y parte de la oposición política. Del otro lado, dichos sectores acusan al gobierno de adquirir un perfil autoritario y lesionar la República. Lo cierto es que esta discusión muestra no solo diferencias políticas sino también grandes intereses en disputa en torno al modelo económico que conducen a una nueva etapa en el debate sobre la democracia.

Tal como lo adelantamos al inicio, en la Argentina de los últimos años se discute la posibilidad de aceptar o no distintas articulaciones entre los componentes de una democracia. Sin rechazar el modelo liberal-democrático occidental, quienes coinciden con el gobierno destacan la necesidad de una rearticulación de esas tradiciones, pero con predominio de la soberanía popular y la igualdad. Quienes se oponen subrayan la urgencia de entender la democracia desde la primacía de sus componentes liberales: división de poderes y derechos individuales. Lo cierto es que el gobierno invoca que para poder llevar adelante los cambios necesarios para una sociedad más equitativa, tomar decisiones es más importante que los procedimientos y la manera cómo se las toma; y los opositores en numerosas ocasiones invocan la institucionalidad para utilizarla solo como un instrumento paralizante de la acción del gobierno. Este debate tiene impacto sobre la PE porque en los países centrales, especialmente en Estados Unidos y Europa, existe un clara asociación entre democracia y liberalismo motivo por el cual, como sostiene Mouffe (2012), en 
ANABella Busso • Los vaivenes de la política exterior argentina re-democratizada...

estos países no existe una comprensión de las experiencias latinoamericanas e, inclusive, se produce un rechazo hacia ellas proveniente no solo de los sectores de derecha sino también de los de izquierda en tanto ambos rechazan nuevas rearticulaciones con predominio de la soberanía popular.

La PE de Cristina, aunque siempre sometida a los vaivenes internos, intenta mantener un perfil autonómico y presenta dos espacios diferenciados. Uno de ellos ligado a los problemas financieros, comerciales y de inversión de Argentina que involucra a los países desarrollados. En este contexto, las relaciones con Estados Unidos han sido bastante inestables pero en la actualidad la agenda abarca temas como la futura decisión de la Corte Suprema de Estados Unidos ante el reclamo de los «holdouts»; la oposición a la postura argentina de no pagar a las empresas americanas beneficiadas por los fallos del CIADI hasta que estas se sometan a la ley nacional y la evolución del acuerdo recientemente firmado entre YPF y la compañía Chevron, para la explotación del yacimiento de Vaca Muerta. Si los Departamentos de Justicia, Estado y Tesoro apoyan en la etapa final del proceso la postura argentina ante los Fondos Buitres y si los sectores opositores internos no paralizan el acuerdo con Chevron, es posible que la relación bilateral viva moderado acercamiento. Por otra parte, las relaciones comerciales y de inversión con China ocupan un espacio en crecimiento, mientras que la postura argentina en referencia a los problemas devenidos de la crisis de 2008 fue planteada por la Presidenta en la Cumbre del G20, aunque las expectativas sobre el éxito de este Grupo han disminuido.

Sin embargo, la dimensión más relevante y dinámica de la PE de Cristina es la latinoamericana. La defensa de la democracia, la resolución de conflictos intraregionales, el fomento de la integración y la defensa de políticas activas aplicadas por algunos gobiernos sudamericanos ante la crisis desatada en 2008, fueron algunos de los ejes de acción. En 2009, ante el debate regional generado por el acuerdo entre Colombia y Estados Unidos para el uso de siete bases militares, Cristina presidió exitosamente una reunión de UNASUR en Bariloche destinada a contener una posible crisis. Argentina también se comprometió positivamente en la Reunión del Grupo de Río en Santo Domingo para tratar de encarar el conflicto entre Ecuador y Colombia por la invasión de este último país a territorio ecuatoriano a los efectos de atacar un campamento de las FARC. Nuestro país también tuvo un rol activo, junto a Brasil, Bolivia, Ecuador y Venezuela, ante el golpe de estado en Honduras $y$, posteriormente, frente al intento desestabilizador encarado por grupos policiales contra el Presidente Rafael Correa. Con antelación, en el contexto de UNASUR, Argentina había apoyado fuertemente al gobierno de Evo Morales ante los intentos secesionistas de los estados de la medialuna. Finalmente, en el contexto del Mercosur, junto a Bra- 
sil y Uruguay, avaló la suspensión del Paraguay hasta que se normalizara la situación política generada por el juicio político «express» a Fernando Lugo.

Asimismo, durante los primeros años de la gestión de Cristina, Néstor Kirchner se involucró más activamente en los temas regionales acompañando el perfil latinoamericanista de la inserción argentina. En este marco, trató de colaborar con la política de liberación de rehenes de las FARC en Colombia y, posteriormente, fue nombrado primer Secretario General de UNASUR.

Esta etapa de la gestión internacional de Argentina fue positiva en tanto no solo consolidó las alianzas con los gobiernos de perfil ideológico similar, sino que mejoró los vínculos con los gobiernos de signo más neoliberal. En este marco, ofreció disculpas al Perú por la venta de armas a Ecuador durante la guerra por la Cordillera del Cóndor y, además, logró un vínculo estable con Chile durante el gobierno de Piñera y mejoró las relaciones con Colombia ante la llegada al poder de Santos.

Además, el gobierno tuvo una participación activa en la oposición a las acciones tomadas por los gobiernos de España, Francia, Italia y Portugal, quienes, violando las normas del derecho internacional, denegaron el uso del espacio aéreo al Presidente Evo Morales en función de un dato de inteligencia equivocado que lo acusaba de llevar en su avión presidencial al ex empleado de la CIA, Edward Snowden.

Esta área de la PE, tan cara a los sentimientos y al proyecto presidencial, enfrenta en 2013 nuevos desafíos que podrían agudizarse en el contexto de finalización del mandato por el desgaste político natural que impone la gestión. En el ámbito interno, el modelo económico afronta dificultades y ausencia de consensos en cuanto a cómo abordarlas. En el contexto externo, se notan las ausencias físicas y políticas de liderazgos como los de Hugo Chávez, Néstor Kirchner y Luiz Inácio Lula da Silva que en cierta medida encaraban la «batalla» en la defensa de los intereses regionales. En este marco, las propuestas neoliberales se reposicionan, o al menos así se lo intenta mostrar desde determinados sectores económicos y mediáticos, subrayando que ahora el éxito pasa por la Alianza del Pacífico conformada por Chile, Perú, Colombia, Costa Rica y México. Esta afirmación, supuestamente conlleva la consolidación del vínculo de estos países con Estados Unidos y el futuro deterioro de UNASUR.

Argentina ha tomado nota de estos cambios y así lo manifestó el discurso presidencial en la última Cumbre de Mercosur (julio de 2013) donde Cristina reclamó reforzar el esfuerzo para continuar con la concertación e integración regional respetando la diversidad de modelos e instrumentos económicos y, así, evitar que dividan a la región desde afuera. Para que el país aporte en esa dirección, tendrá que resolver los diferendos comerciales con los vecinos más cercanos y conseguir un mayor nivel de inversión nacional e internacional. Estas condiciones son significativas para 
AnAbella Busso • Los vaivenes de la política exterior argentina re-democratizada...

mantener las políticas industrialistas y de generación de empleo que hacen tanto al desarrollo nacional como a la relación positiva entre el gobierno y la sociedad y facilitan los diseños de una PE autonómica.

\section{A MODO DE CIERRE}

Sin dudas, la PE en la Argentina re-democratizada ha sufrido cambios y ajustes que mejoraron la imagen del país en términos comparativos con la situación de aislamiento en que la había dejado el régimen militar, pero no lograron optimizar su inserción de la manera esperada. Dichos cambios y ajustes, como en cualquier otro país, se vincularon con las transformaciones producidas en el orden internacional devenidas del fin de la guerra fría y la compleja evolución de los escenarios de posguerra fría, pero en el caso argentino respondieron mayoritariamente a situaciones internas.

El país ha transitado un camino de crisis económico-políticas cíclicas que deterioraron su cohesión interna e impactaron sobre la PE debilitando las condiciones de negociación internacional; fijaron los principales temas de agenda externa e, inclusive, consumieron la atención de los presidentes que debían atender permanentemente amenazas de inestabilidad institucional, situaciones hiperinflacionarias o crisis multidimensionales como la de 2001. Esta última puede ser caracterizada como un «colapso estatal» que dejó al país en una situación de aislamiento financiero internacional, pobreza, ingobernabilidad y descreimiento político generalizado a nivel nacional.

Por otra parte, como sostuvimos a lo largo de este trabajo, Argentina aún no resolvió su disputa histórica entre dos modelos desarrollo que, además de ser opuestos, conllevan distintas alternativas de inserción internacional. En este sentido, la puja de intereses contrapuestos se agudizó en cada una de las situaciones de crisis aumentando la profundidad de las mismas con la intención de que, a la salida de dichas crisis, se lograse el triunfo de un determinado modelo de acumulación y una determinada inserción. El breve repaso histórico que hemos realizado muestra cómo los actores financieros, las grandes empresas, los grandes productores agropecuarios, los medios de comunicación y los sindicatos, fueron, en mayor o menor medida, partícipes centrales buscando condicionar los niveles de apertura económica, el valor de la moneda, la orientación de las alianzas políticas y económicas internacionales, etc. Esta es una de las explicaciones de los permanentes cambios y ajustes de la PE que han llevado a los especialistas a describirla como errática e inconsistente.

Cada una de estas situaciones de crisis reforzó inicialmente el liderazgo presidencial de quien llegaba a la Casa Rosada y les permitió desacreditar las ideas de sus antecesores y predisponer a la sociedad para que le concediera al gobierno una oportunidad para resol- 
ver la emergencia vía una nueva etapa fundacional. Dicho en otras palabras, cada alternativa para enfrentar las crisis significaba reformular las políticas públicas, entre ellas la PE. Aquí tenemos otra de las razones que explican los permanentes cambios y ajustes en la acción externa del país. Así pasamos de una propuesta de PE autonomista y su giro realista a una política de alineamiento con Estados Unidos, para volver en nuestros días a una propuesta autonomista y latinoamericanista. Estas instancias estuvieron acompañadas por alternativas de organización económica de base desarrollista o de base neoliberal y todas terminaron fracasando y generando un nuevo escenario de crisis.

En este marco, resulta importante subrayar que la clase política tuvo, con distintos grados de enfrentamientos domésticos y éxito, más intenciones de restablecer un equilibrio en la relación entre Estado y Mercado y su respectivo impacto sobre el desarrollo de las políticas internas y externa en las etapas alfonsinista y kirchnerista que durante el menemismo cuando primó la idea de que no había otra alternativa que el acoplamiento al neoliberalismo y el alineamiento con Estados Unidos.

En nuestros días, la discusión se ahonda porque existe una correlación entre ciertos sectores económicos y políticos que profundiza la polarización y afecta la estabilidad macroeconómica y política. Consecuentemente, no solo las propuestas de PE de cada sector son diferentes, sino que la acción externa del gobierno argentino es evaluada desde perspectivas extremas. Una señala su carácter confrontativo y su inconsistencia, la otra subraya su perfil autonomista, latinoamericanista e industrialista. El debate nacional no se ha saldado y, por lo tanto, la relación entre democracia y PE permanece abierta a situaciones de cambio y ajuste sometidos a la lógica interna.

\section{Bibliografía}

Alfonsín, Raúl (1983), «Discurso ante la Honorable Asamblea Legislativa tras asumir la Presidencia de la Nación», Buenos Aires, 10 de diciembre de 1983.

Cantero, Fernando (2012) ¿Grinspun fue un accidente?, Página 12, Buenos Aires, 22 de enero.

Collier, D. y Levistky, S. (1997), «Democracy with Adjectives: Conceptual Innovation in Comparative Research", World Politics, Vol. 49, $\mathrm{N}^{\circ} 3$.

De Pablo, Juan Carlos, (2009), Política Económica en Democracia. De Alfonsín a Kirchner, Buenos Aires, Educa.

Ferrer, Aldo (2010), El futuro de nuestro pasado. La economía argentina en su segundo centenario. Buenos Aires. Fondo de Cultura Económica.

Garretón, Manuel Antonio (2004), «La indispensable y problemática relación entre partidos y democracia en América Latina», en PNUD 2004, La democracia en América Latina. Hacia una democracia de ciudadanas y ciudadanos. Contribuciones para el debate, Buenos Aires: PNUD.

Garretón, Manuel Antonio (2006) «América Latina: la política desplaza a la economía», Diario Clarín, Buenos Aires, 20 de agosto.

Lafer, Celso, (2002), La identidad internacional de Brasil, Buenos Aires. Fondo de Cultura Económica. 
AnAbella Busso • Los vaivenes de la política exterior argentina re-democratizada...

Lavagna, Roberto, (2005) «Hacia otra dimensión de país», Revista Archivos del Presente, año 10, número 37, Buenos Aires.

Menem, Carlos (1990), Estados Unidos, Argentina y Carlos Menem, Buenos Aires, Editorial CEYNE.

Mouffe, Chantal (2012) «Hay que latinoamericanizar Europa», entrevista realizada por Javier Lorca, Diario Página 12, Buenos Aires, 21 de octubre. Recuperado el 16 de mayo de 2013 de http://www.pagina12.com.ar/diario/elpais/1-206036-2012-10-21.html

O’Donnell, Guillermo; (1994) «Delegative Democracy», Journal of Democracy, Vol.5, No. 1, January, National Endowment for Democracy and The Johns Hopkins University Press, 55-69.

Palermo Vicente y Juan Carlos Torre, «A la sombra de la hiperinflación. La política de reformas estructurales en Argentina», 1994. Recuperado el 5 de agosto de 2013 en http://www.cipol.org/pdfs/Palermo.pdf

Peruzzotti, Enrique (1998), "La emergencia de una política de Derechos Humanos en la sociedad civil argentina», Documento de Trabajo Universidad Torcuato Di Tella, Buenos Aires.

Pignatta, María Eva (2010) «Identidad y Política Exterior. Explorando el caso argentino» en Busso Anabella (comp.)
Fuerzas Profundas e Identidad. Reflexiones sobre su impacto en la política exterior. Un recorrido de casos, Tomo II, Rosario, Argentina, E-Book, UNR Editora.

Pignatta, María Eva, (2011) «Multilateralismo y defensa de la democracia: el accionar de la Organización de Estados Americanos frente a crisis político-institucionales (1990-2009), (Tesis Doctoral, Universidad Nacional de Rosario).

Rapoport, Mario (2010), Historia económica, política y social de la Argentina (18802003), Buenos Aires, Emecé, $4^{a}$ Edición.

Rapoport, Mario y Claudio (2005), Política Exterior Argentina. Poder y Conflictos internos, Buenos Aires, Capital Intelectual.

Russell, Roberto, (1990) «Política exterior y toma de decisiones en América Latina: aspectos comparativos y consideraciones teóricas", en edición preparada por Russell, Roberto, Política exterior y toma de decisión en América Latina, Bs. As., GEL, pág. 225.

Whitehead, Lawrence (1993), «The Alternative to Liberal Democracy: a Latin American Perspective», en David Held (ed.) Prospects for Democracy, Cambridge: Polity Press. 